\title{
Mathematical Model of Free Convection Boundary Layer Flow on Solid Sphere with Viscous Dissipation and Thermal Radiation
}

\author{
Muhammad Khairul Anuar Mohamed, Mohd Zuki Salleh, Abid Hussanan, Norhafizah Md Sarif, Nor Aida \\ Zuraimi Md Noar, Anuar Ishak and Basuki Widodo
}

\begin{abstract}
Present study considers the mathematical modeling of free convection boundary layer flow and heat transfer on a solid sphere with viscous dissipation and thermal radiation effects. The transformed partial differential equations are solved numerically by using the Keller-box method. Numerical solutions are obtained for the reduced Nusselt number, the local skin friction coefficient, the velocity and temperature profiles. The features of the flow characteristics for various values of the Prandtl number, radiation parameter and Eckert number are discussed. It is worth mentioning that the results are obtained until $x=180^{\circ}$. This is contrary to the previous report where the separation boundary layer flow occurs after $x=120^{\circ}$. The results in this paper is important for the researchers working in the area of boundary layer flow and this can be used as reference and also as complement for comparison purposes in the future.
\end{abstract}

Index Terms-Mathematical modeling, free convection boundary layer flow, solid sphere, viscous dissipation, thermal radiation.

\section{INTRODUCTION}

C ONVECTION boundary layer flow on a solid sphere becomes an important topic due to numerous engineering and industrial applications such as the spherical storage tanks and turbocharged ball bearing in automotives segment. The efficiency of lubricating and heat removes process (convection) in turbocharged unit definitely depends on design of the turbocharged itself, the flow, conductivity, viscosity and the characteristic of the fluid used.

The exact analysis on laminar free convection from a sphere was first investigated by Chiang et al. [1]. Amato and Tien [2] have worked on the experimental studies on free convection heat transfer from isothermal spheres in water. The experimental result obtained shows a very good agreement with predictions of Acrivos theory. Geoola and Cornish [3]

Manuscript received June 6, 2016; accepted June 21, 2016. This work was supported by Universiti Malaysia Pahang (RDU150101). Corresponding author: M.Z. Salleh (phone: 609-5492203; fax: 609-5492766).

M.K.A. Mohamed, M.Z. Salleh, A. Hussanan, N.M. Sarif and N.A.Z. Noar are with the Applied \& Industrial Mathematics Research Group, Fakulti Sains \& Teknologi Industri, Universiti Malaysia Pahang, 26300 UMP Kuantan, Pahang, Malaysia. Emails: baa_khy@yahoo.com, zukikuj@yahoo.com, abidhussnain_utm@yahoo.com, norhafizah@ump. edu.my, aidaz@ump.edu.my

A. Ishak was with the School of Mathematical Sciences, Fakulti Sains \& Teknologi, Universiti Kebangsaan Malaysia, 43600 UKM Bangi, Selangor, Malaysia. Email: anuar_mi@ukm.edu.my

B. Widodo is with the Department of Mathematics, Institut Teknologi Sepuluh Nopember, Surabaya 60111, Indonesia. Email: b_widodo@matematika.its.ac.id have solved the steady-state free convective from a solid sphere using an extrapolated Gauss-Seidel method and obtained solutions for Grashof number less than 50. Next, Huang and Chen [4] have investigated this topic with the effects of suction and blowing while Jafarpur and Yovanovich [5] introduced a new analytical method in solving the laminar free convective from isothermal sphere. This problem has been extended to micropolar fluid by Nazar et al. [6], [7] by considering constant wall temperature and constant surface heat flux. Shafie et al. [8], Molla et al. [9] and Miraj et al. [10] studied the effect of g-jitter on double diffusion, magnetohydrodynamic, heat generation and thermal radiation on natural convection flow on sphere, respectively. Salleh et al. [11] considered the Newtonian heating as boundary conditions in this topic before extended it with micropolar fluid [12]. Other type of fluids considered including viscoelastic fluid which have been covered by Kasim et al. [13] and recently by Abdul Gaffar et al. [14] by considering the thermal radiation and heat generation/absorption effects in porous media with constant surface heat flux, respectively.

In considering the viscous dissipation effects, we know that the viscous dissipation is the induced kinetic energy converted into thermal energy. It is usually present in free convection subjected to large deccelaration from high rotating speeds [15]. Soundalgekar [16] has solved the viscous dissipation effects on unsteady free convective flow past an infinite, vertical porous plate with constant suction analytically. Vajravelu and Hadjinicolaou [17], Murthy and Singh [18], Tunc and Bayazitoglu [19] and Chen [20] have investigated the viscous dissipation effects on viscous fluid over a stretching surface, non-Darcy regime, microtubes and vertical surface, respectively. Many investigations have been made regarding the viscous dissipation effects including from the works of Olanrewaju et al. [21], Kameswaran et al. [22], RamReddy et al. [23] and recently by Qasim and Noreen [24] and Sheikholeslami et al. [25].

Based on the above contribution, the aim of present study is to investigate the free convective boundary layer flow on a solid sphere with viscous dissipation and thermal radiation effects.

\section{Mathematical Formulations}

A solid sphere with radius $a$, which is heated to a constant temperature $T_{w}$ embedded in a viscous fluid with ambient tem- 
perature $T_{\infty}$ is considered. The model and physical coordinate system is shown in Fig. 1.

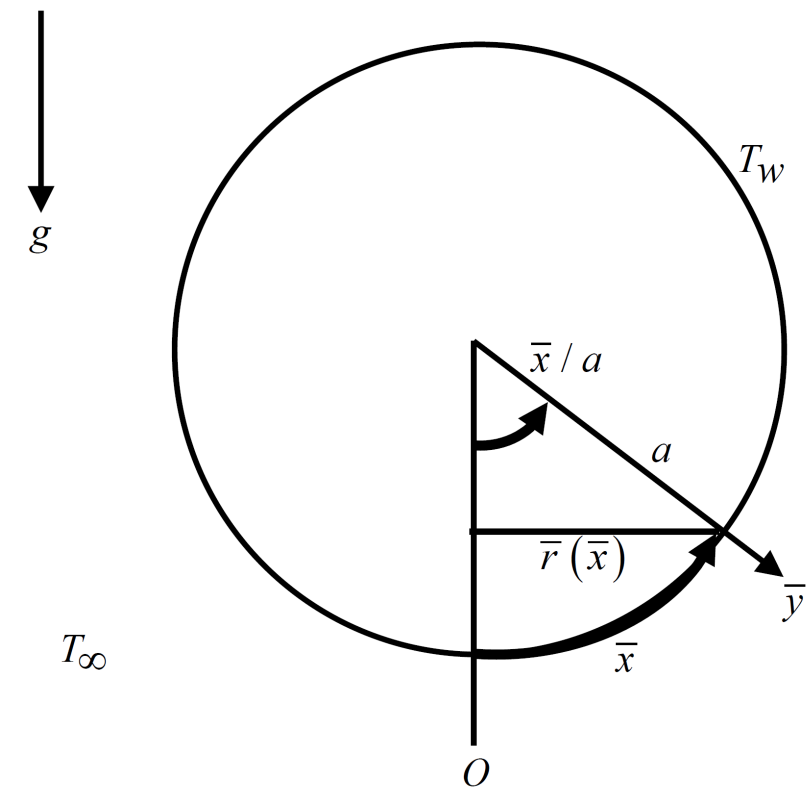

Fig. 1. Coordinate system of the physical model.

The orthogonal coordinates of $\bar{x}$ are measured along the sphere surface, starting from the lower stagnation point $(\bar{x}=$ 0 ) and $\bar{y}$ measures the distance normal to the surface of the sphere. We define $\bar{r}(\bar{x})=a \sin (\bar{x} / a)$ as the radial distance from the symmetrical axis to the surface of the sphere. Based on Nazar et al. [6] and Salleh et al. [11], the dimensional governing equations are

$$
\begin{aligned}
& \frac{\partial}{\partial \bar{x}}(\bar{r} \bar{u})+\frac{\partial}{\partial \bar{y}}(\bar{r} \bar{v})=0 \\
& \bar{u} \frac{\partial \bar{u}}{\partial \bar{x}}+\bar{v} \frac{\partial \bar{u}}{\partial \bar{y}}=\nu \frac{\partial^{2} \bar{u}}{\partial \bar{y}^{2}}+g \beta\left(T-T_{\infty}\right) \sin (\bar{x} / a) \\
& \bar{u} \frac{\partial T}{\partial \bar{x}}+\bar{v} \frac{\partial T}{\partial \bar{y}}=\frac{k}{\rho C_{p}} \frac{\partial^{2} T}{\partial \bar{y}^{2}}+\frac{\mu}{\rho C_{p}}\left(\frac{\partial \bar{u}}{\partial \bar{y}}\right)^{2}-\frac{1}{\rho C_{p}} \frac{\partial q_{r}}{\partial \bar{y}}
\end{aligned}
$$

subject to the boundary conditions

$$
\begin{array}{ll}
\bar{u}(\bar{x}, 0)=\bar{v}(\bar{x}, 0)=0, & T(\bar{x}, 0)=T_{w}, \\
\bar{u}(\bar{x}, \infty) \rightarrow 0, & T(\bar{x}, \infty) \rightarrow T_{\infty},
\end{array}
$$

where $\bar{u}$ and $\bar{v}$ are the velocity components along the $\bar{x}$ and $\bar{y}$ axes, respectively. $\mu$ is dynamic viscosity, $\nu$ is the kinematic viscosity, $g$ is the gravitt acceleration, $k$ is the thermal conductivity, $\beta$ is the thermal expansion, $T$ is the local temperature, $\rho$ is the fluid density and $C_{p}$ is the specific heat capacity at a constant pressure. The radiative heat flux $q_{r}$ can be simplified as

$$
q_{r}=-\frac{4 \sigma^{*}}{3 k^{*}} \frac{\partial T^{4}}{\partial y}
$$

where $\sigma^{*}$ and $k^{*}$ are the Stefan-Boltzmann constant and the mean absorption coefficient, respectively. Using Rosseland approximation [26], (3) is reduced to

$$
\bar{u} \frac{\partial T}{\partial \bar{x}}+\bar{v} \frac{\partial T}{\partial \bar{y}}=\left(\frac{k}{\rho C_{p}}+\frac{16 \sigma^{*} T_{\infty}^{3}}{3 k^{*} \rho C_{p}}\right) \frac{\partial^{2} T}{\partial \bar{y}^{2}}+\frac{\mu}{\rho C_{p}}\left(\frac{\partial \bar{u}}{\partial \bar{y}}\right)^{2} .
$$

From the above equation, we can see that the effect of radiations is to enhance the thermal diffusivity. If we define $N_{R}=\frac{4 \sigma^{*} T_{\infty}^{3}}{k k^{*}}$ as the radiation parameter, then (6) becomes

$$
\bar{u} \frac{\partial T}{\partial \bar{x}}+\bar{v} \frac{\partial T}{\partial \bar{y}}=\frac{k}{\rho C_{p}}\left(1+\frac{4}{3} N_{R}\right) \frac{\partial^{2} T}{\partial \bar{y}^{2}}+\frac{\mu}{\rho C_{p}}\left(\frac{\partial \bar{u}}{\partial \bar{y}}\right)^{2} .
$$

Note that thermal radiation effects are absent when $N_{R}=0$. Next, we introduce the governing non-dimensional variables

$$
\begin{aligned}
& r=\frac{\bar{r}}{a}, x=\frac{\bar{x}}{a}, \quad y=G r^{1 / 4} \frac{\bar{y}}{a}, \quad u=\frac{a}{v} G r^{-1 / 2} \bar{u} \\
& v=\frac{a}{v} G r^{-1 / 4} \bar{v}, \quad \theta(\eta)=\frac{T-T_{\infty}}{T_{w}-T_{\infty}},
\end{aligned}
$$

where $G r=\frac{g \beta\left(T_{w}-T_{\infty}\right) a^{3}}{v^{2}}$ is the Grashof number. Using (8), (1), (2) and (7) becomes the following dimensionless governing equations

$$
\begin{aligned}
& \frac{\partial}{\partial x}(r u)+\frac{\partial}{\partial y}(r v)=0, \\
& u \frac{\partial u}{\partial x}+v \frac{\partial u}{\partial y}=\frac{\partial^{2} u}{\partial y^{2}}+\theta \sin x, \\
& u \frac{\partial \theta}{\partial x}+v \frac{\partial \theta}{\partial y}=\frac{1}{P r}\left(1+\frac{4}{3} N_{R}\right) \frac{\partial^{2} \theta}{\partial y^{2}}+E c\left(\frac{\partial u}{\partial y}\right)^{2},
\end{aligned}
$$

subject to the boundary conditions

$$
\begin{array}{ll}
u(x, 0)=v(x, 0)=0, & \theta(x, 0)=1, \\
u(x, \infty) \rightarrow 0, & \theta(x, \infty) \rightarrow 0
\end{array}
$$

Notice that $\operatorname{Pr}=\frac{\nu k}{\rho C_{p}}$ is the Prandtl number and $E c=$ $\frac{\nu^{2} G r}{a^{2} C_{p}\left(T_{w}-T_{\infty}\right)}$ is an Eckert number. In order to solve (9)-(11), the following functions are introduced

$$
\psi=x r(x) f(x, y), \quad \theta=\theta(x, y),
$$

where $\psi$ is the stream function, which is defined as $u=\frac{1}{r} \frac{\partial \psi}{\partial y}$ and $v=-\frac{1}{r} \frac{\partial \psi}{\partial x}$ that satisfies (9) and $\theta$ is the rescaled dimensionless temperature of the fluid. If we substitute (14) into (10)-(11), the following transformed partial differential equations are obtained

$$
\begin{gathered}
\frac{\partial^{3} f}{\partial y^{3}}+\left(1+\frac{x}{\sin x} \cos x\right) f \frac{\partial^{2} f}{\partial y^{2}}-\left(\frac{\partial f}{\partial y}\right)^{2}+ \\
\frac{\sin x}{x} \theta=x\left(\frac{\partial f}{\partial y} \frac{\partial^{2} f}{\partial x \partial y}-\frac{\partial f}{\partial x} \frac{\partial^{2} f}{\partial y^{2}}\right), \\
\frac{1}{P r}\left(1+\frac{4}{3} N_{R}\right) \frac{\partial^{2} \theta}{\partial y^{2}}+\left(1+\frac{x}{\sin x} \cos x\right) f \frac{\partial \theta}{\partial y}= \\
x\left(\frac{\partial f}{\partial y} \frac{\partial \theta}{\partial x}-\frac{\partial f}{\partial x} \frac{\partial \theta}{\partial y}-x E c\left(\frac{\partial^{2} f}{\partial y^{2}}\right)^{2}\right),
\end{gathered}
$$

with boundary conditions

$$
\begin{array}{ll}
f(x, 0)=0, \frac{\partial f}{\partial y}(x, 0)=0, & \theta(x, 0)=1 \\
\frac{\partial f}{\partial y}(x, \infty) \rightarrow 0, & \theta(0, \infty) \rightarrow 0 .
\end{array}
$$


The physical quantities of interest are the skin friction coefficient $C_{f}=\frac{\tau_{w}}{\rho u_{\infty}^{2}}$ and the local Nusselt number $N u_{x}=$ $\frac{a q_{w}}{k\left(T_{w}-T_{\infty}\right)}$ where the surface shear stress $\tau_{w}$ and the surface heat flux $q_{w}$ are given by

$$
\tau_{w}=\mu\left(\frac{\partial \bar{u}}{\partial \bar{y}}\right)_{\bar{y}=0}, \quad q_{w}=-k\left(\frac{\partial T}{\partial \bar{y}}\right)_{\bar{y}=0} .
$$

From (14) and (18), we obtain

$$
C_{f} G r^{1 / 4}=x \frac{\partial^{2} f}{\partial y^{2}}(x, 0) \text { and } N u_{x} G r^{-1 / 4}=-\frac{\partial \theta}{\partial y}(x, 0) .
$$

\section{NUMERICAL METHOD}

The partial differential equations (15) and (16) subject to boundary conditions (17) are solved numerically using the Keller-box method. This method is an implicit finite-difference method in conjunction with Newton's method for linearization. This is a suitable method to solve parabolic partial differential equations. The previous studies which use the Keller-box method in solving boundary layer problems including Ishak et al. [27], [28], Nazar et al. [29], [30] and Salleh et al. [31], [32]. As described in the books by $\mathrm{Na}$ [33] and Cebeci and Bradshaw [34], the Keller-box method consists of four main steps:

1) reduce (15) and (16) to a first-order system,

2) write the difference equations using central differences,

3) linearize the resulting algebraic equations by Newton's method, and write them in the matrix-vector form,

4) solve the linear system by the block tridiagonal elimination technique.

\section{RESULTS AND Discussions}

Equations (15)-(16) with boundary conditions (17) are solved with three parameters considered namely the Prandtl number $P r$, radiation parameter $N_{R}$ and Eckert number $E c$. Keller-box method is used to solve this problem. The boundary layer thickness $y_{\infty}=12$ and step size $\Delta y=0.02$ are used in obtaining the numerical results. It is worth mentioning that the numerical results obtained are not limited until $x=120^{\circ}$ as reported previously by Huang and Chen [4], Nazar et al. [6] and Salleh et al. [11]. The solution is obtained to the end of sphere $\left(x=180^{\circ}\right)$. Table 1 shows the comparison values with previous published results. We found that the results are in a good agreement. Furthermore we believe that Keller-box method is proven to be very efficient to solve the convective boundary layer problems involving reduced partial differential equations.

Figures 2 and 3 show the variation of reduced skin friction coefficient $C_{f} G r^{1 / 4}$ against $x$ with various values of $\operatorname{Pr}, E c$ and $N_{R}$, respectively. From both figures, we can see that the increment of $x$ results in the increment of $C_{f} G r^{1 / 4}$ in the middle of sphere surface before decreasing $C_{f} G r^{1 / 4} \approx 0$ at the end of sphere.

Figures 4 and 5 illustrate the variation of reduced Nusselt number $N u_{x} G r^{-1 / 4}$ against $x$ with various values of $\mathrm{Pr}, E c$ and $N_{R}$, respectively. We can see that $N u_{x} G r^{-1 / 4}$ in Figs. 4 and 5 is decreasing w.r.t. $x$. From Fig. 4, it seems that
TABLE I

COMPARISON VALUES OF $N u_{x} G r^{-1 / 4}$ WITH PREVIOUS PUBLISHED RESULTS FOR VARIOUS VALUES OF $x$.

\begin{tabular}{|c|c|c|c|c|}
\hline$x$ & $\begin{array}{c}\text { Huang and } \\
\text { Chen [4] }\end{array}$ & $\begin{array}{c}\text { Nazar et } \\
\text { al. [6] }\end{array}$ & $\begin{array}{c}\text { Salleh et } \\
\text { al. [11] }\end{array}$ & Present \\
\hline $0^{\circ}$ & 0.4574 & 0.4576 & 0.4576 & 0.4576 \\
$10^{\circ}$ & 0.4563 & 0.4565 & 0.4565 & 0.4565 \\
$20^{\circ}$ & 0.4532 & 0.4533 & 0.4533 & 0.4533 \\
$30^{\circ}$ & 0.4480 & 0.4480 & 0.4481 & 0.4480 \\
$40^{\circ}$ & 0.4407 & 0.4405 & 0.4406 & 0.4406 \\
$50^{\circ}$ & 0.4312 & 0.4308 & 0.4310 & 0.4310 \\
$60^{\circ}$ & 0.4194 & 0.4198 & 0.4195 & 0.4195 \\
$70^{\circ}$ & 0.4053 & 0.4046 & 0.4053 & 0.4053 \\
$80^{\circ}$ & 0.3886 & 0.3879 & 0.3886 & 0.3886 \\
$90^{\circ}$ & 0.3694 & 0.3684 & 0.3692 & 0.3692 \\
$100^{\circ}$ & & & 0.3470 & 0.3469 \\
$110^{\circ}$ & & & 0.3216 & 0.3215 \\
$120^{\circ}$ & & & 0.2925 & 0.2925 \\
$130^{\circ}$ & & & & 0.2594 \\
$140^{\circ}$ & & & & 0.2216 \\
$150^{\circ}$ & & & & 0.1795 \\
$160^{\circ}$ & & & & 0.1265 \\
$170^{\circ}$ & & & & 0.0712 \\
$180^{\circ}$ & & & & 0.0045 \\
\hline
\end{tabular}

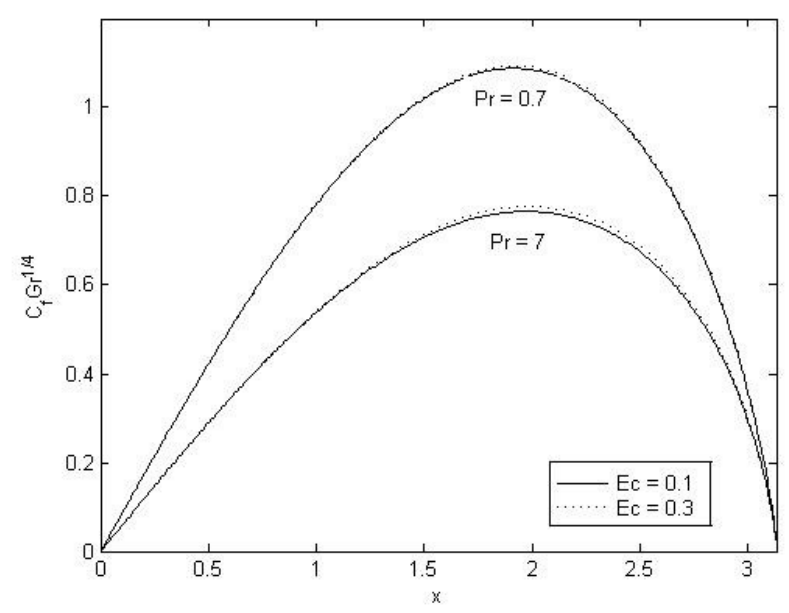

Fig. 2. Variation of $C_{f} G r^{1 / 4}$ against $x$ with various values of $P r$ and $E c$ when $N_{R}=1$

when $\mathrm{Pr}$ increases, the value of $N u_{x} G r^{-1 / 4}$ also increases, which physically means that bigger value of $\operatorname{Pr}$ contributes to the enhancement of convective heat transfer process. Next, the increment on $E c$ implies the reduction on the value of $N u_{x} G r^{-1 / 4}$. Also, the $E c$ effect is more pronounced with bigger value of $\mathrm{Pr}$. This is due to the large kinetic energy offered from large $\mathrm{Pr}$ then converted to the thermal energy which enhance the conduction effects. From Fig. 5, the increase of $N_{R}$ gives the reduction in $N u_{x} G r^{-1 / 4}$. The effect of changes in $N_{R}$ is the most pronounced at the stagnation region $(x=0)$. Furthermore, we found that all set of parameters give $N u_{x} G r^{-1 / 4} \approx 0$, which physically means that no convection or the conduction process occurs at the end of sphere.

Finally, Figs. 6, 7, 8 and 9 display the temperature $\theta(y)$ and velocity profiles $f^{\prime}(y)$ for various values of $\operatorname{Pr}$ and $N_{R}$, respectively. From Fig. 6, observe that the increase of $\mathrm{Pr}$ results in the decrease of boundary layer thickness. This is 


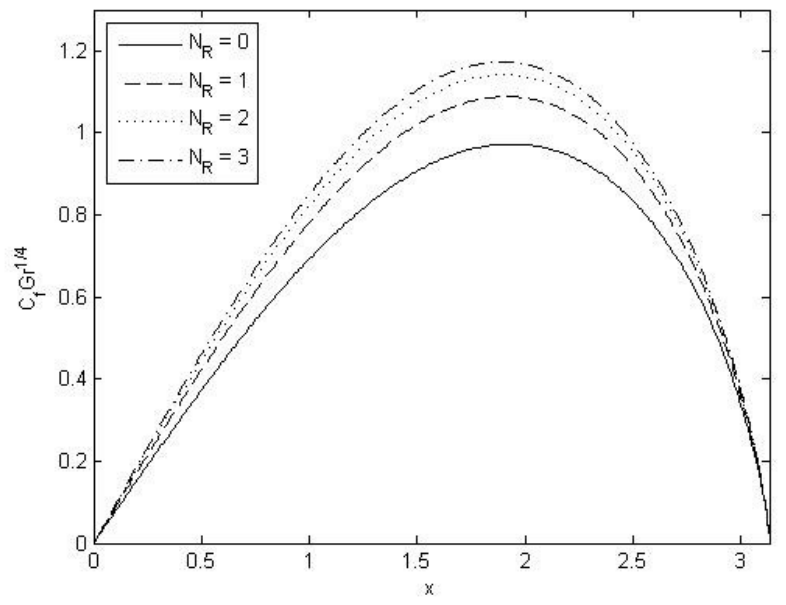

Fig. 3. Variation of $C_{f} G r^{1 / 4}$ against $x$ with various values of $N_{R}$ when $\operatorname{Pr}=0.7$ and $E c=0.1$

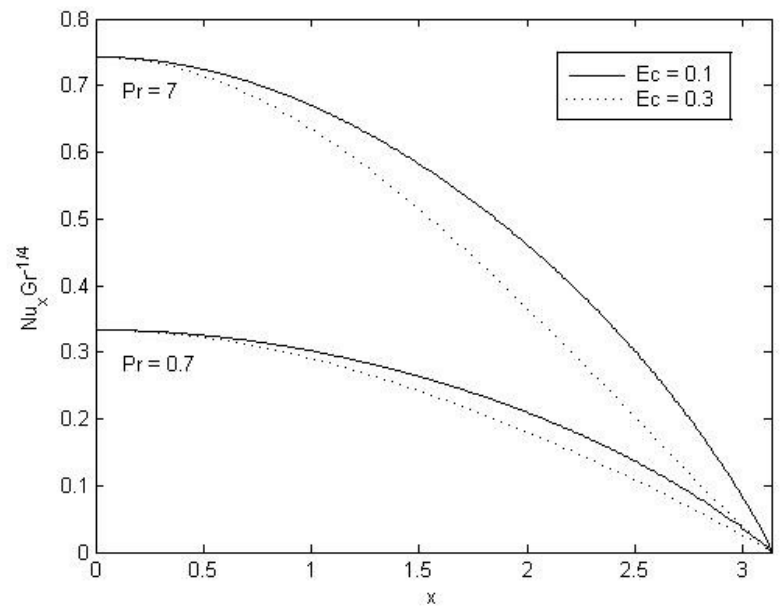

Fig. 4. Variation of $N u_{x} G r^{-1 / 4}$ against $x$ with various values of $\operatorname{Pr}$ and $E c$ when $N_{R}=1$.

due to a decrease of thermal diffusivity, which leads to the reduction in energy ability that reduces the thermal boundary layer thickness as $\mathrm{Pr}$ increases. Meanwhile, the increase of $N_{R}$ enhances the boundary layer thickness. The velocity profiles in Fig. 8 suggest that the increase of $\operatorname{Pr}$ reduces the velocity of the fluid and the velocity gradient which results in the decrease of skin friction coefficients. The situation is contrary with $N_{R}$ in Fig. 9. Boundary layer thickness increases as $N_{R}$ increases. Furthermore, it is worth mentioning that the $E c$ does not have any effect on $\theta(y)$ and $f^{\prime}(y)$. It is clear from (15) and (16) that at stagnation region $(x=0), E c$ is terminated from the equations.

\section{CONCLUSIONS}

In this paper, the mathematical modeling of free convection boundary layer flow on solid sphere with viscous dissipation and thermal radiation effects has been solved numerically. We have shown how the Prandtl number $P r$, radiation parameter

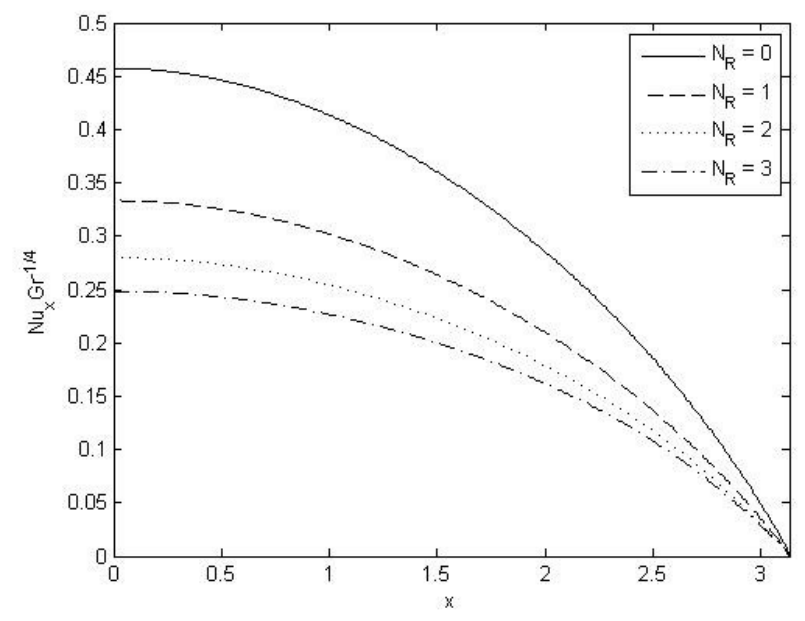

Fig. 5. Variation of $N u_{x} G r^{-1 / 4}$ against $x$ with various values of $N_{R}$ when $\operatorname{Pr}=0.7$ and $E c=0.1$

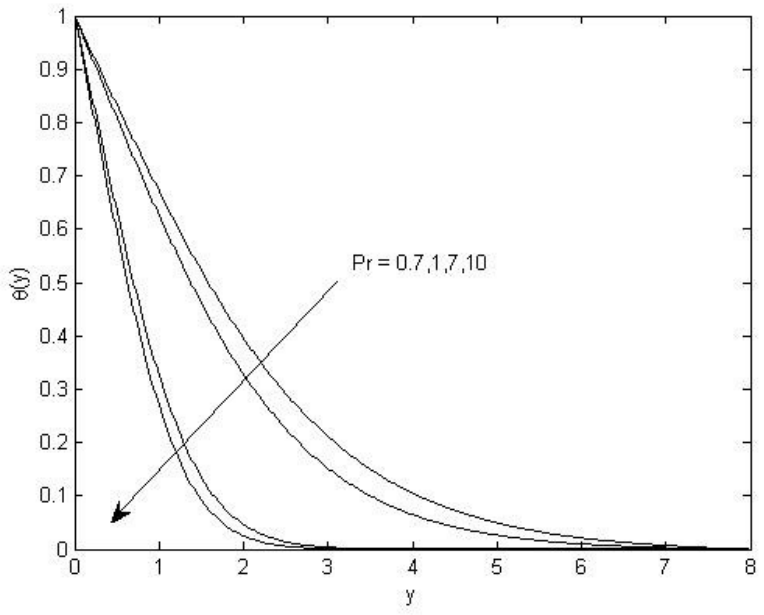

Fig. 6. Temperature profiles $\theta(y)$ for various values of $\operatorname{Pr}$ when $N_{R}=1$ and $E c=0.1$.

$N_{R}$ and Eckert number $E c$ affect the values of the reduced Nusselt number and reduced skin friction coefficient as well as the velocity and temperature profiles.

As a conclusion, the increase of $\operatorname{Pr}$ results in the increase of reduced Nusselt number while reduced skin friction coefficient decreases. $P r$ gives huge effects to the flow compared to $E c$. Conversely, the increase of $N_{R}$ enhances the reduced skin friction coefficient while the reduced Nusselt number decreases. Furthermore, the increase of $E c$ gives small increment on the reduced skin friction coefficient but decrease the reduced Nusselt number. Note that $E c$ is more pronounced with the large value of $\mathrm{Pr}$.

Next, the increase in $P r$ reduces the thermal boundary layer thickness, the velocity of the fluid and the velocity gradient which results in the decrease of skin friction coefficients. Meanwhile, the thermal boundary layer thickness and the velocity of the fluid increase as $N_{R}$ increases. 


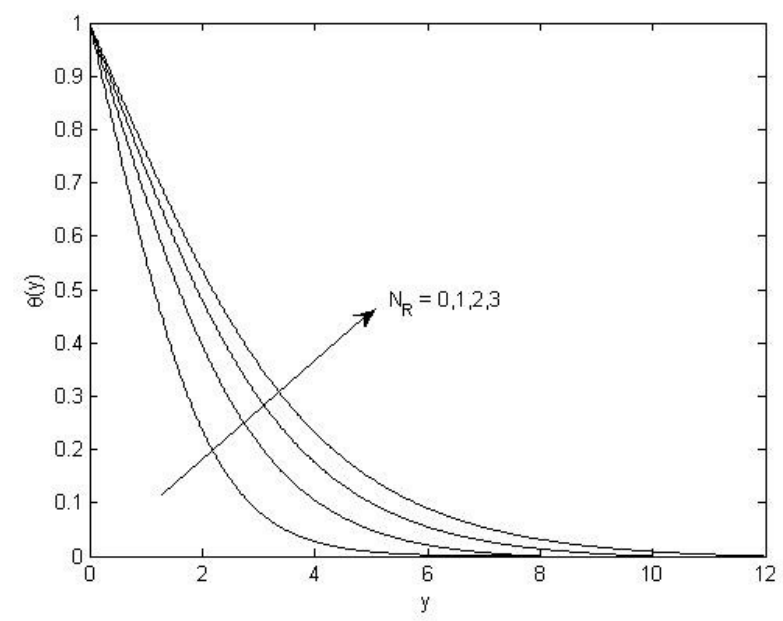

Fig. 7. Temperature profiles $\theta(y)$ for various values of $N_{R}$ when $\operatorname{Pr}=0.7$ and $E c=0.1$.

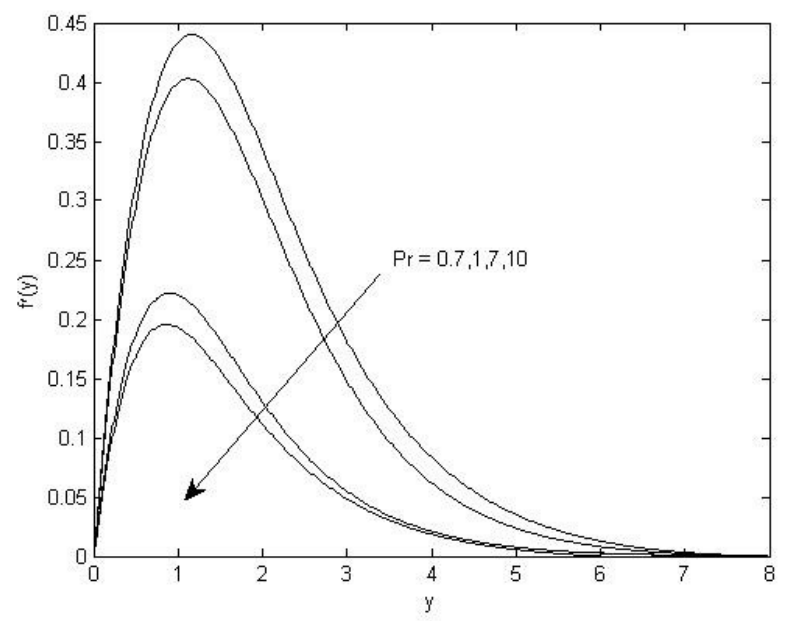

Fig. 8. Velocity profiles $f^{\prime}(y)$ for various values of $\operatorname{Pr}$ when $N_{R}=1$ and $E c=0.1$

\section{ACKNOWLEDGMENT}

The authors would like to acknowledge Universiti Malaysia Pahang for the financial supports with code number RDU140111 (FRGS) and RDU150101 (FRGS).

\section{REFERENCES}

[1] T. Chiang, A. Ossin, and C. Tien, "Laminar free convection from a sphere," Journal of Heat Transfer, vol. 86, no. 4, pp. 537-541, 1964.

[2] W. Amato and T. Chi, "Free convection heat transfer from isothermal spheres in water," International Journal of Heat and Mass Transfer, vol. 15 , no. 2, pp. 327-339, 1972.

[3] F. Geoola and A. Cornish, "Numerical solution of steady-state free convective heat transfer from a solid sphere," International Journal of Heat and Mass Transfer, vol. 24, no. 8, pp. 1369-1379, 1981.

[4] M.-J. Huang and C. Chen, "Laminar free convection from a sphere with blowing and suction," Journal of Heat Transfer, vol. 109, no. 2, pp. 529-532, 1987.

[5] K. Jafarpur and M. Yovanovich, "Laminar free convective heat transfer from isothermal spheres: a new analytical method," International Journal of Heat and Mass Transfer, vol. 35, no. 9, pp. 2195-2201, 1992.

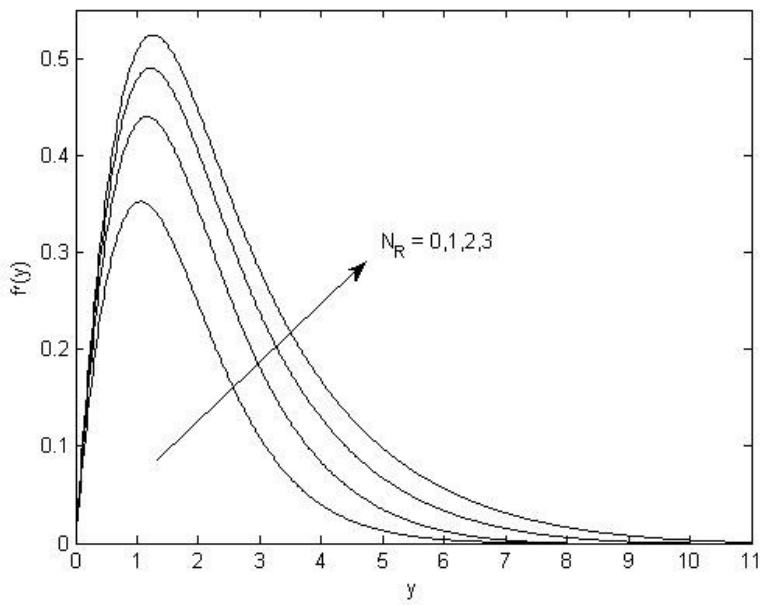

Fig. 9. Velocity profiles $f^{\prime}(y)$ for various values of $N_{R}$ when $\operatorname{Pr}=0.7$ and $E c=0.1$.

[6] R. Nazar, N. Amin, T. Groşan, and I. Pop, "Free convection boundary layer on an isothermal sphere in a micropolar fluid," International Communications in Heat and Mass Transfer, vol. 29, no. 3, pp. 377-386, 2002.

[7] _ _ "Free convection boundary layer on a sphere with constant surface heat flux in a micropolar fluid," International Communications in Heat and Mass Transfer, vol. 29, no. 8, pp. 1129-1138, 2002.

[8] S. Shafie, N. Amin, and I. Pop, "The effect of g-jitter on double diffusion by natural convection from a sphere," International Journal of Heat and Mass Transfer, vol. 48, no. 21, pp. 4526-4540, 2005.

[9] M. Molla, M. Hossain, and M. Taher, "Magnetohydrodynamic natural convection flow on a sphere with uniform heat flux in presence of heat generation," Acta Mechanica, vol. 186, no. 1-4, pp. 75-86, 2006.

[10] M. Miraj, M. Alim, and M. Mamun, "Effect of radiation on natural convection flow on a sphere in presence of heat generation," International Communications in Heat and Mass Transfer, vol. 37, no. 6, pp. 660-665, 2010.

[11] M. Salleh, R. Nazar, and I. Pop, "Modeling of free convection boundary layer flow on a solid sphere with newtonian heating," Acta Applicandae Mathematicae, vol. 112, no. 3, pp. 263-274, 2010.

[12] _ - "Numerical solutions of free convection boundary layer flow on a solid sphere with newtonian heating in a micropolar fluid," Meccanica, vol. 47, no. 5, pp. 1261-1269, 2012.

[13] A. Kasim, N. Mohammad, A. Aurangzaib, and S. Shafie, "Natural convection boundary layer flow past a sphere with constant heat flux in viscoelastic fluid," Jurnal Teknologi, vol. 62, no. 3, 2013.

[14] S. Abdul Gaffar, V. Ramachandra Prasad, E. Keshava Reddy, and O. Anwar Bég, "Thermal radiation and heat generation/absorption effects on viscoelastic double-diffusive convection from an isothermal sphere in porous media," Ain Shams Engineering Journal, vol. 6, no. 3, pp. 10091030, 2015.

[15] B. Gebhart, "Effects of viscous dissipation in natural convection," Journal of Fluid Mechanics, vol. 14, no. 02, pp. 225-232, 1962

[16] V. Soundalgekar, "Viscous dissipation effects on unsteady free convective flow past an infinite, vertical porous plate with constant suction," International Journal of Heat and Mass Transfer, vol. 15, no. 6, pp. 1253-1261, 1972.

[17] K. Vajravelu and A. Hadjinicolaou, "Heat transfer in a viscous fluid over a stretching sheet with viscous dissipation and internal heat generation," International Communications in Heat and Mass Transfer, vol. 20, no. 3, pp. 417-430, 1993.

[18] P. Murthy and P. Singh, "Effect of viscous dissipation on a non-darcy natural convection regime," International Journal of Heat and Mass Transfer, vol. 40, no. 6, pp. 1251-1260, 1997.

[19] G. Tunc and Y. Bayazitoglu, "Heat transfer in microtubes with viscous dissipation," International Journal of Heat and Mass Transfer, vol. 44, no. 13, pp. 2395-2403, 2001.

[20] C.-H. Chen, "Combined heat and mass transfer in mhd free convection from a vertical surface with ohmic heating and viscous dissipation," 
International Journal of Engineering Science, vol. 42, no. 7, pp. 699713, 2004.

[21] P. Olanrewaju, J. Gbadeyan, O. Agboola, and S. Abah, "Radiation and viscous dissipation effects for the blasius and sakiadis flows with a convective surface boundary condition," International Journal of Advances in Science and Technology, vol. 2, no. 4, pp. 102-115, 2011.

[22] P. Kameswaran, M. Narayana, P. Sibanda, and P. Murthy, "Hydromagnetic nanofluid flow due to a stretching or shrinking sheet with viscous dissipation and chemical reaction effects," International Journal of Heat and Mass Transfer, vol. 55, no. 25, pp. 7587-7595, 2012.

[23] C. RamReddy, P. Murthy, A. Chamkha, and A. Rashad, "Influence of viscous dissipation on free convection in a non-darcy porous medium saturated with nanofluid in the presence of magnetic field," The Open Transport Phenomena Journal, vol. 5, pp. 20-29, 2013.

[24] M. Qasim and S. Noreen, "Heat transfer in the boundary layer flow of a casson fluid over a permeable shrinking sheet with viscous dissipation," The European Physical Journal Plus, vol. 129, no. 1, pp. 1-8, 2014.

[25] M. Sheikholeslami, S. Abelman, and D. Ganji, "Numerical simulation of mhd nanofluid flow and heat transfer considering viscous dissipation," International Journal of Heat and Mass Transfer, vol. 79, pp. 212-222, 2014.

[26] R. Bataller, "Radiation effects for the blasius and sakiadis flows with a convective surface boundary condition," Applied Mathematics and Computation, vol. 206, no. 2, pp. 832-840, 2008.

[27] A. Ishak, R. Nazar, and I. Pop, "Mixed convection boundary layers in the stagnation-point flow toward a stretching vertical sheet," Meccanica, vol. 41, no. 5, pp. 509-518, 2006.

[28] A. Ishak, R. Nazar, N. Arifin, and I. Pop, "Mixed convection of the stagnation-point flow towards a stretching vertical permeable sheet," Malaysian Journal of Mathematical Sciences, vol. 1, no. 2, pp. 217226, 2007.

[29] R. Nazar, N. Amin, and I. Pop, "Mixed convection boundary-layer flow from a horizontal circular cylinder in micropolar fluids: case of constant wall temperature," International Journal of Numerical Methods for Heat \& Fluid Flow, vol. 13, no. 1, pp. 86-109, 2003.

[30] R. Nazar, N. Amin, D. Filip, and I. Pop, "Stagnation point flow of a micropolar fluid towards a stretching sheet," International Journal of Non-Linear Mechanics, vol. 39, no. 7, pp. 1227-1235, 2004.

[31] M. Salleh, R. Nazar, and I. Pop, "Forced convection boundary layer flow at a forward stagnation point with newtonian heating," Chemical Engineering Communications, vol. 196, no. 9, pp. 987-996, 2009.

[32] M. Salleh, R. Nazar, N. Arifin, and I. Pop, "Numerical solutions of forced convection boundary layer flow on a horizontal circular cylinder with newtonian heating," Malaysian Journal of Mathematical Sciences, vol. 5, no. 2, pp. 161-184, 2011

[33] T. Na, Computational Methods in Engineering Boundary Value Problems. New York: Academic Press, 1979.

[34] P. Bradshaw and T. Cebeci, Physical and Computational Aspects of Convective Heat Transfer. New York: Springer-Verlag, 1984. 